\title{
THE STATE-DEPENDENT RESOURCE ALLOCATION HYPOTHESIS: IMPLICATIONS FOR THE FORAGING ECOLOGY AND LIFE HISTORY OF MIGRATORY UNGULATES IN THE GYE
}

\author{
-

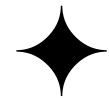 \\ MATTHEW J. KAUfFMAN $\uparrow$ KEVIN L. MONTEITH $\uparrow$ BRETT R. JESMER \\ UNIVERSITY OF WYOMING $\uparrow$ LARAMIE, WY
}

\section{$\downarrow \quad$ INTRODUCTION}

Understanding the behavioral and physiological responses of animals to environmental stressors is vital to our comprehension of their ecology and life history. The life-history strategy of ungulates is for females to prioritize survival over reproductive effort to maximize life-long fitness (Stearns 1992, Eberhardt 2002, Bårdsen et al. 2008). Consequently, an individual's reproductive decisions are expected to be dependent on nutritional state (Bårdsen et al. 2008). Researchers have long assumed that individuals reduce their metabolism and energy expenditure to conserve nutritional reserves (i.e., fat and protein) during winter because winter has been demonstrated to be a period of energetic loss for temperate ungulates. Recent research, however, has shown that mule deer (Odocoileus hemionus) in a poor nutritional state are capable of increasing their nutritional reserves over winter (Monteith et al. 2013), and hormone analysis of moose (Alces alces; Jesmer et al. in review) indicates that animals with low nutritional reserves have high energy expenditure and energy intake. Therefore, regulation of nutritional state through plasticity in foraging behavior may allow animals to cope with resource shortages. We refer to this notion, wherein animals alter their energy intake and expenditure via foraging behavior as the StateDependent Resource Allocation Hypothesis (Figure 1). In 2014 we proposed to apply state-of-the-art nutritional, isotopic, and hormone analyses to test the State-Dependent Resource Allocation Hypothesis (SRAH) in migratory mule deer within the Greater Yellowstone Ecosystem.
Stable isotope analyses facilitate the study of foraging behavior by quantifying the relative proportions of metabolic fuels derived from exogenous (forage) and endogenous (internal tissue) sources. The carbon isotope signatures $\left(\delta^{13} \mathrm{C}\right)$ of certain non-essential amino acids differ depending on whether its carbon is derived from endogenous (in this case fat tissue) or exogenous sources (Newsome et al. 2011, Whiteman et al. 2015). Additionally, nitrogen isotope signatures $\left(\delta^{15} \mathrm{~N}\right)$ are useful for studies of foraging behavior because $\delta^{15} \mathrm{~N}$ values vary considerably between ungulate tissue and dietary items, permitting the quantification of endogenous (in this case muscle protein) and exogenous sources of protein (Taillon et al. 2013). For mule deer that may be exhibiting state-dependent foraging strategies, synthesizing amino acids from endogenous sources would result in low quantity of $\delta^{13} \mathrm{C}$ in a protein rich substrate (e.g., red blood cells), whereas amino acids synthesized from exogenous sources results in greater amounts of $\delta^{13} \mathrm{C}$ (DeNiro and Epstein 1977). Conversely, mule deer relying more heavily on endogenous protein sources have higher quantities of $\delta^{15} \mathrm{~N}$ in red blood cells when compared to individuals deriving protein primarily from forage. Additionally, thyroid hormones, such as triiodothyronine (T3), may be useful in the study of state-dependent foraging because T3 plays an important role in regulating metabolism, where higher circulating $\mathrm{T} 3$ reflects a higher metabolic rate (Zheng et al. 2014). Finally, by affixing collars to mule deer with onboard global positioning systems, foraging activity can be quantify based on a variety of movement parameters (Gurarie et al. 2016). Thus, the combination of stable isotope, hormone, and movement analyses provides a powerful framework for studying state-dependent foraging. 
To elucidate the influence of foraging decisions on nutritional state, reproduction, and survival, we began testing two primary predictions of the SRAH:

\section{Foraging and catabolism prediction}

Mule deer in poor nutritional condition will have higher energy intake (T3) and increased foraging activity (movement), resulting in red blood cells containing more $\mathrm{C}$ and $\mathrm{N}$ derived from forage than from somatic tissues (catabolism). Mule deer in good nutritional condition will have lower energy intake and reduced foraging activity, resulting in red blood cells containing more $\mathrm{C}$ and $\mathrm{N}$ derived from somatic tissues than from forage.

\section{Life history prediction}

Mule deer will regulate their nutritional reserves in a manner that will optimize life-long fitness (i.e., survival and reproduction). To increase their probability of survival and future reproduction, individuals that have a surplus of nutritional reserves will reduce metabolism to conserve energy and forage less to minimize their exposure to sources of potential mortality. Individuals in a nutritional deficit will have high metabolic rates to support foraging activities and the synthesis of nutritional reserves needed for survival and future reproduction.

\section{$\uparrow \quad$ METHODS}

\section{Nutritional state}

During 2013-2016, approximately 95 female mule deer were captured twice annually: once when they arrive onto winter range in December, and once just before they begin spring migration in March. All methods were approved by the University of Wyoming Animal Care and Use committee and the Wyoming Game and Fish Department. Ultrasonography and body condition scoring were used in tandem to calculate total nutritional reserves in the form of both fat and protein per the methodologies of Monteith et al. (2013). December values of fat and protein reserves provided an accurate measure of nutritional state at the beginning of winter. March values of fat and protein reserves allowed us to calculate the over winter change in both reserves. The amount of fat and protein an individual has in December will determine the nutritional state of the individual at the beginning of winter and guide our predictions of the relationships between foraging and activity profiles.

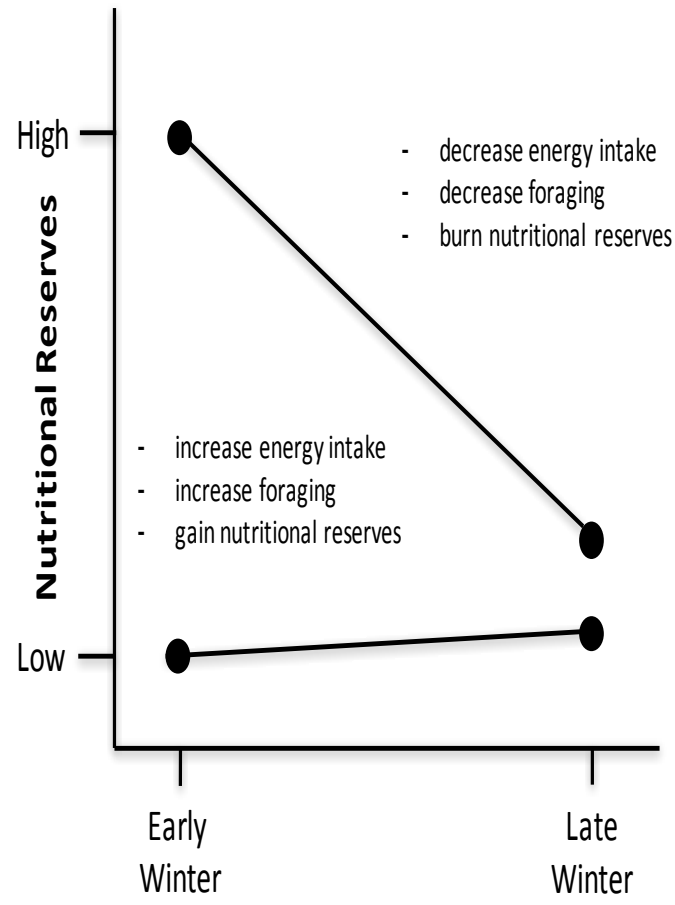

Figure 1. Conceptual figure illustrating the observed trends in nutritional gains and losses (circles and lines) over winter (Monteith et al. 2013). Predictions of the State-Dependent Resource Allocation Hypothesis (hashed bullets) are outlined for individuals with relatively high and low nutritional reserves.

\section{Sampling design}

The distribution of body fat losses from fall 2014 through spring 2015 ranged from -6 percentage points (fat loss) to positive 1 percentage point (fat gain). Therefore, during fall 2015 captures we collected red blood cells, feces, and biopsied muscle and fat (somatic tissue) from the rump of deer after applying a local anesthetic, from 4 individuals within each 1 percentage point bins ( 8 total bins, $n=32$ ).

\section{Movement}

Each captured mule deer was fit with a global positioning system (GPS) collar that recorded the location of the individual once every hour. The spatial location data was used to quantify the proportion of time each individual spent in a behavioral state, i.e., foraging, bedding, and moving between foraging and bedding sites. We are using a Bayesian state-space model that uses step lengths (the distance between successive locations), turning angles, and movement of the neck (tilt meter inside the collar; more tilts when foraging than when bedded) to assign each location as belonging to one of the three behavioral states (Ditmer et al. unpublished, Morales et al. 2004, Gurarie et al. 2016). 


\section{Stable isotopes and hormones}

Red blood cells reflect the sources of $\delta^{13} \mathrm{C}$ and $\delta^{15} \mathrm{~N}$ during the 4-8-week period prior to sample collection, and are therefore appropriate for our research. We collected red blood cells during both December and March captures. While isotopic values of fat and muscle tissue provide an isotopic signature of body reserves, plant fibers found in the fecal sample provide an isotopic signature of forage. Red blood cells, fat tissue, muscle tissue, and plant fibers found in feces were sent to the University of New Mexico, Center for Stable Isotopes for analysis of $\delta^{13} \mathrm{C}$ and $\delta^{15} \mathrm{~N}$. Additional whole fecal samples were collected at time of capture and will be sent to the University of Washington, Conservation Biology Lab for T3 analysis.

\section{Life history}

We annually monitored nutrition, reproduction and survival in all study animals. Survival of female mule deer was monitored using GPS collar-based mortality sensors. These sensors emit a faster pulse rate once the collar has not moved for five hours. Hence, we performed mortality surveys every two weeks as we search for individuals while conducting time budget observations. During March capture we assessed fetal rates (presence and number of fetuses) using trans-abdominal ultrasonography (Monteith et al. 2014).

\section{$\uparrow \quad$ RESULTS}

We have only completed exploratory lab and statistical analyses at this time because funding for this study came in two installments $(1 / 2$ in 2014 , and $1 / 2$ in 2016). Changes in lean body mass (protein reserves) and body fat overwinter were dependent on the amount of these reserves individuals possessed in the fall when they returned to winter range from their summer ranges. Although most mule deer lost reserves overwinter, individuals that entered winter with few fat and protein reserves tended to lose fewer reserves overwinter. Interestingly, some individuals gained fat or protein overwinter (Figure 2). These results demonstrate that physiological or behavioral plasticity allows mule deer to overcome the nutritional limitations presented by winter in temperate climates - an important first step in our study.

Despite previous reports of statistically significant correlations between bulk $\delta^{13} \mathrm{C}$ or $\delta^{15} \mathrm{~N}$ and body fat or lean mass in lab rodents and other small vertebrates, linear regression revealed no pattern between $\delta^{13} \mathrm{C}$ or $\delta^{15} \mathrm{~N}$ and body fat or lean mass in
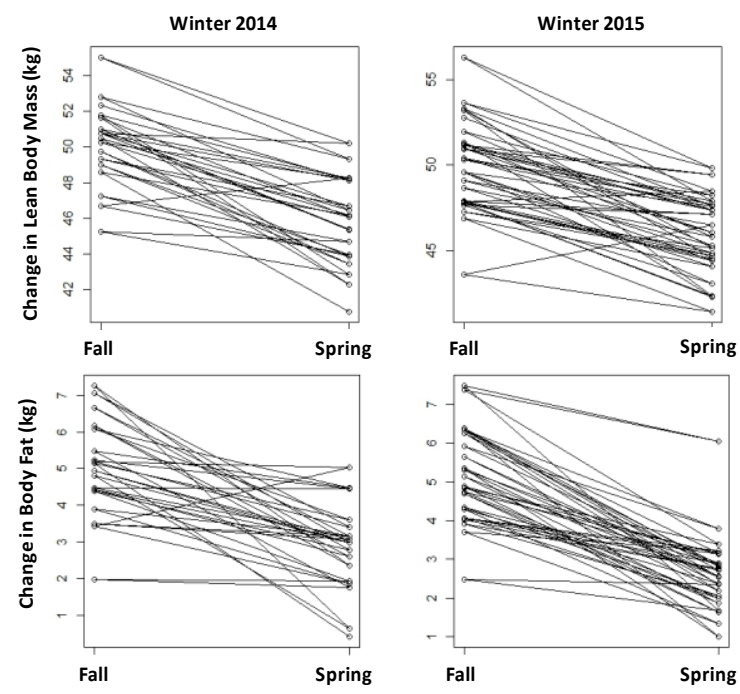

Figure 2. Schematic demonstrating that individuals who entered winter with few fat and protein reserves tended to lose fewer reserves overwinter. Some individuals gained fat or protein overwinter. Open circles represent individual nutritional reserves in fall (December) and spring (March), and black lines illustrated the degree to which nutritional reserves were lost or gained overwinter.

mule deer (all $\mathrm{P}>0.2$ ). This result, however, did not surprise us. The large and diverse microbial community found in the rumen of large herbivores, such as ungulates, is capable of synthesizing many types of amino acids (the building blocks of somatic tissues) that monogastric animals, such as lab rodents, cannot (Church 1988, Puniya et al. 2015). Bulk isotope analysis (used here) quantifies $\delta^{13} \mathrm{C}$ and $\delta^{15} \mathrm{~N}$ for the entire (red blood cell) sample and thus all amino acids. Some amino acids can be synthesized by the body (somatic cell) and some must be acquired in the diet, thus understanding the contribution of $\mathrm{C}$ and $\mathrm{N}$ from the somatic reserves versus diet may be necessary to elucidate patterns of state-dependent foraging.

\section{$\downarrow \quad$ CONTINUED WORK}

We are currently investigating which amino acids can be synthesized endogenously (from microbes or catabolism of somatic tissues; nonessential amino acids) by ruminants and which amino acids can only be acquired from forage (essential amino acids). Once this investigation is complete we will use compound-specific amino acid analyses to quantify $\delta^{13} \mathrm{C}$ and $\delta^{15} \mathrm{~N}$ in the non-essential amino acids of red blood cells (i.e., amino acids that are synthesized within somatic cells), such that we can develop overwinter catabolism and foraging profiles for each mule deer. Once isotopic methodologies and 
analyses are complete we will begin linking foraging (energy intake [T3] and movement) and catabolism profiles (stable isotopes) to life history characteristics (i.e., reproduction and survival), thereby providing a test of the SRAH.

\section{$\downarrow \quad$ Literature CiTED}

Bårdsen, B. J., P. Fauchald, T. Tveraa, K. Langeland, N. G. Yoccoz, and R. A. Ims. 2008. Experimental evidence of a risk-sensitive reproductive allocation in a long-lived mammal. Ecology 89:829-837.

Church, D. C. 1988. The ruminant animal: Digestive physiology and nutrition. Prentice-Hall, Englewood Cliffs, NJ.

DeNiro, M. J., and S. Epstein. 1977. Mechanism of carbon isotope fractionation associated with lipid synthesis. Science 197:261-263.

Eberhardt, L. L. 2002. A paradigm for population analysis of long-lived vertebrates. Ecology 83:2841-2854.

Gurarie, E., C. Bracis, M. Delgado, T. D. Meckley, I. Kojola, and C. M. Wagner. 2016. What is the animal doing? Tools for exploring behavioural structure in animal movements. Journal of Animal Ecology 85:69-84.

Jesmer, B. R., J. R. Goheen, K. L. Monteith, and M. J. Kauffman. in review. State-dependent foraging alters endocrine-energy relationships in a large herbivore. Ecological Applications.

Monteith, K. L., V. C. Bleich, T. R. Stephenson, B. M. Pierce, M. M. Conner, J. G. Kie, and R. T. Bowyer. 2014. Life-history characteristics of mule deer: Effects of nutrition in a variable environment. Wildlife Monographs 186:162.
Monteith, K. L., T. R. Stephenson, V. C. Bleich, M. M. Conner, B. M. Pierce, and R. T. Bowyer. 2013. Risk-sensitive allocation in seasonal dynamics of fat and protein reserves in a long-lived mammal. J Anim Ecol 82:377388.

Morales, J. M., D. T. Haydon, J. Frair, K. E. Holsinger, and J. M. Fryxell. 2004. Extracting more out of relocation data: Building movement models as mixtures of random walks. Ecology 85:2436-2445.

Newsome, S. D., M. L. Fogel, L. Kelly, and C. M. del Rio. 2011. Contributions of direct incorporation from diet and microbial amino acids to protein synthesis in nile tilapia. Functional Ecology 25:1051-1062.

Puniya, A. K., R. Singh, and D. N. Kamra. 2015. Rumen microbiology: From evolution to revolution. Springer.

Stearns, S. C. 1992. The evolution of life histories. OUP Oxford.

Taillon, J., P. S. Barboza, and S. D. Cote. 2013. Nitrogen allocation to offspring and milk production in a capital breeder. Ecology 94:1815-1827.

Whiteman, J., H. Harlow, G. M. Durner, R. AndersonSprecher, S. E. Albeke, E. V. Regehr, S. C. Amstrup, and M. Ben-David. 2015. Summer declines in activity and body temperature offer polar bears limited energy savings. Science 349:295-298.

Zheng, W. H., J. S. Liu, and D. L. Swanson. 2014. Seasonal phenotypic flexibility of body mass, organ masses, and tissue oxidative capacity and their relationship to resting metabolic rate in chinese bulbuls. Physiological and Biochemical Zoology 87:432-444. 